EXPERIMENTAL STUDY

\title{
Localization of glucocorticoid receptor interacting protein 1 in murine tissues using two novel polyclonal antibodies
}

\author{
Rami Puustinen ${ }^{1,2}$, Nanna Sarvilinna ${ }^{1,2}$, Tommi Manninen ${ }^{1,2}$, Pentti Tuohimaa ${ }^{3}$ and Timo Ylikomi ${ }^{1,4}$ \\ ${ }^{1}$ Department of Cell Biology, Medical School, University of Tampere, FIN-33014, Tampere, ${ }^{2}$ Institute of Medical Technology, \\ University of Tampere, PO Box 607, FIN-33101, Tampere, ${ }^{3}$ Department of Anatomy, Medical School, University of Tampere, FIN-33014, Tampere, and \\ ${ }^{4}$ Department of Clinical Chemistry, Tampere University Hospital, PO Box 2000, FIN-33521, Tampere, Finland \\ (Correspondence should be addressed to R Puustinen or N Sarvilinna; Email: rp58671@uta.fi or nu56352@uta.fi)
}

\begin{abstract}
Objective: Glucocorticoid receptor interacting protein 1 (GRIP1) is a coactivator that binds to the nuclear hormone receptors in a ligand-dependent manner and mediates transcriptional activation of the target genes. The aim of this study was to investigate GRIP1 expression in various murine tissues and whether the protein is nuclear, cytoplasmic, or both.

Design: Two novel polyclonal antibodies against amino acids $34-47$ and 468-481 of GRIP1 were raised and characterized in order to study the GRIP1 expression with immunohistochemistry.

Results: Transient transfection studies with COS cells showed a clearly nuclear staining pattern and also immunohistochemical localization of GRIP1 was mainly nuclear, but cytoplasmic expression was seen as well. GRIP1 was expressed in epithelial cells of the submandibular gland, gastrointestinal tract, pancreas, kidney, uterus, mammary gland, testis, prostate, trachea, lungs and adrenal gland. GRIP1 was also detected in stromal cells of colon, rectum, urinary bladder, vagina, uterus, mammary gland and trachea, and to a lesser extent in esophagus, ureter, urethra, thymus and spleen. Smooth muscle cells of the gastrointestinal and urinary tract, uterus, epididymis, prostrate and bronchioles expressed GRIP1. Blood vessels of many organs, capsule of the kidney and prostate, mesovarium, adipocytes of the mammary gland, pericardium and cartilage of the trachea were also GRIP1-positive. Liver, thyroid gland and striated muscle did not express GRIP1.

Conclusions: GRIP1 was expressed in a wide variety of murine organs, and expression varied between cell types and organs. In addition to mainly nuclear localization of endogenous GRIP1, cytoplasmic expression was seen as well.
\end{abstract}

European Journal of Endocrinology 145 323-333

\section{Introduction}

Nuclear hormone receptors (NRs) are transcriptional activators, which have many different roles in the regulation of cell functions as well as in the growth and differentiation of various tissues and organs (1). Most of them have similar functional domains, which include a highly conserved DNA-binding domain, an N-terminal region containing constitutive activation function AF-1, and a C-terminal multifunctional ligand-binding domain (LBD), which includes ligand-dependent activation function AF-2 within the distal C-terminus $(2-4)$. Transcriptional activation and repression by the NRs is mediated through coactivators and corepressors $(5,6)$. Transcription intermediary factor 2 (TIF2) (7) and its murine homolog glucocorticoid receptor interacting protein 1 (GRIP1) $(8,9)$, as well as steroid receptor coactivator 1 (SRC-1) $(10,11)$, ACTR (12), amplified in breast cancer-1 (AIB1) (13), thyroid hormone receptor activator molecule
(TRAM1) (4) and steroid/nuclear receptor associated coactivator-3 (RAC3) (15), also known as CBPassociated factor (16), are highly related; they share $\sim 40 \%$ sequence identity and form a family of $160 \mathrm{kDa}$ coactivators. Treuter et al. (17) have suggested that p160 coactivators might be degradation products of larger proteins, such as thyroid hormone receptor associated protein-220 (TRAP220).

GRIP1/TIF2 has been shown to interact with several NRs, including glucocorticoid receptor (GR), estrogen receptor (ER) and androgen receptor (AR) (8), progesterone receptor (PR), mineralocorticoid receptor, thyroid hormone receptor- $\alpha(\mathrm{TR} \alpha)$, vitamin-D receptor (VDR), retinoid X receptor- $\alpha(\mathrm{RXR} \alpha)$ and retinoic acid receptor- $\alpha(\operatorname{RAR} \alpha)(9)$, retinoid-related orphan receptor- $\alpha$ (18), ERR3 (19), HNF $4 \alpha$ (20), estrogenrelated receptor- $\alpha-1$ (ERR $\alpha-1)$ (21) and peroxisome proliferator-activated receptor (17). GRIP1 and TIF2 are believed to interact with AF-2 of the NRs through three short leucine-rich signature motifs (LXXLL) called 
Table 1 GRIP1 expression in different murine organs and cell types.

\begin{tabular}{|c|c|c|c|c|c|}
\hline \multirow[b]{2}{*}{ Organ } & \multicolumn{5}{|c|}{ Cell types } \\
\hline & Epithelial & Stromal & Smooth muscle & Blood vessels & Capsular \\
\hline \multicolumn{6}{|l|}{ Gastrointestinal } \\
\hline Esophagus & $(+)^{1}$ & $(+)$ & $(+)$ & $\mathrm{N} / \mathrm{A}$ & $N / A$ \\
\hline Stomach & $+^{2}$ & - & + & $N / A$ & $\mathrm{~N} / \mathrm{A}$ \\
\hline Small intestine & $t^{2}$ & - & + & $\mathrm{N} / \mathrm{A}$ & N/A \\
\hline Cecum & $+^{2}$ & - & $+1+^{2}$ & $\mathrm{~N} / \mathrm{A}$ & $\mathrm{N} / \mathrm{A}$ \\
\hline Colon and rectum & $++^{2}$ & + & + & $\mathrm{N} / \mathrm{A}$ & $\mathrm{N} / \mathrm{A}$ \\
\hline Submandibular gland & + & - & $\mathrm{N} / \mathrm{A}$ & - & - \\
\hline Liver & - & - & $N / A$ & + & - \\
\hline Pancreas & $(+) /+^{3}$ & $N / A$ & -4 & + & $\mathrm{N} / \mathrm{A}$ \\
\hline \multicolumn{6}{|l|}{ Urogenital } \\
\hline Kidney & + & - & $N / A$ & + & + \\
\hline Ureter & - & $(+)$ & $(+)$ & $\mathrm{N} / \mathrm{A}$ & N/A \\
\hline Urinary bladder & - & + & + & + & $+{ }^{5}$ \\
\hline Urethra & + & $(+)$ & $(+)$ & $N / A$ & $\mathrm{~N} / \mathrm{A}$ \\
\hline Vagina & - & + & $\mathrm{N} / \mathrm{A}$ & $\mathrm{N} / \mathrm{A}$ & N/A \\
\hline Uterus & + & + & + & + & $+{ }^{5}$ \\
\hline Ovary & - & - & $\mathrm{N} / \mathrm{A}$ & N/A & $+^{6}$ \\
\hline Mammary gland & + & + & N/A & $\mathrm{N} / \mathrm{A}$ & $+^{7}$ \\
\hline Testis & + & $N / A$ & $\mathrm{~N} / \mathrm{A}$ & $\mathrm{N} / \mathrm{A}$ & - \\
\hline Epididymis & - & - & + & $\mathrm{N} / \mathrm{A}$ & - \\
\hline Prostate & $+^{2}$ & $\mathrm{~N} / \mathrm{A}$ & + & $\mathrm{N} / \mathrm{A}$ & + \\
\hline \multicolumn{6}{|l|}{ Cardiopulmonary } \\
\hline Heart & - & - & -8 & + & $++^{9}$ \\
\hline Trachea & + & + & $N / A$ & N/A & $++^{10}$ \\
\hline Lungs & + & $N / A$ & + & + & $\mathrm{N} / \mathrm{A}$ \\
\hline \multicolumn{6}{|l|}{ Endocrinological } \\
\hline Adrenal gland & + & - & N/A & $\mathrm{N} / \mathrm{A}$ & - \\
\hline Thyroid gland & - & - & $\mathrm{N} / \mathrm{A}$ & - & $\mathrm{N} / \mathrm{A}$ \\
\hline \multicolumn{6}{|l|}{ Other organs } \\
\hline Thymus & $\mathrm{N} / \mathrm{A}$ & $(+)$ & $\mathrm{N} / \mathrm{A}$ & - & - \\
\hline Spleen & $\mathrm{N} / \mathrm{A}$ & $(+)$ & $\mathrm{N} / \mathrm{A}$ & - & - \\
\hline Striated muscle & $\mathrm{N} / \mathrm{A}$ & $\mathrm{N} / \mathrm{A}$ & - & $\mathrm{N} / \mathrm{A}$ & $N / A$ \\
\hline
\end{tabular}

Nuclear expression is weak $(+)$, present + or absent,$-{ }^{1}$ Staining in basal parts of the epithelium, ${ }^{2}$ cytoplasmic staining, ${ }^{3}$ exocrine epithelium was weakly stained while islets of Langerhans had clear expression, ${ }^{4}$ pancreatic ducts, ${ }^{5}$ surrounding connective tissue, ${ }^{6}$ mesovarium, ${ }^{7}$ surrounding adipocytes, ${ }^{8}$ cardiac muscle, ${ }^{9}$ pericardium and ${ }^{10}$ cartilage. $\mathrm{N} / \mathrm{A}=$ not applicable.

NR boxes, which are also present in other AF-2-binding proteins like human receptor interacting-protein 140 , mouse CBP/p300 (CREB-binding protein/CBP-related protein p300), mouse TIF1 and human thyroid hormone receptor interacting-protein (TRIP) proteins (22). These NR boxes form so-called nuclear receptor interaction domains (NIDs) and they all display preferences in binding for certain receptors (22-27). A basic helix-loop-helix region adjacent to the LXXLL motif seems to be important for efficient TIF2-receptor interactions (25). The NR box binds to a small $\left(\sim 300 \AA^{3}\right)$ hydrophobic surface cleft in the LBD and the coactivator binding surface is formed in response to an active hormone by positioning helix 12 against a scaffold formed by helixes 3, 5 and 6 (28).

In addition to NID, there is another C-terminal region of GRIP1 (amino acids 1011-1121), called the auxiliary NID, which cannot directly bind to the NR but is required for efficient interaction with GR, AR and $\operatorname{RAR} \alpha$ (27). On the other hand, $\operatorname{PR}, \operatorname{RXR} \alpha, \operatorname{TR} \beta 1$ and VDR require only NID for efficient interaction (27).
There is evidence suggesting that transcriptional activation by AF-1 of some steroid receptors is mediated through p160 coactivators, and it has been shown that transcriptional activation is induced more when AF-1 and AF- 2 of ER, PR and GR act in synergy than when they act separately $(29,30)$. Ma et al. (31) have found a specific C-terminal region of GRIP1 $\left(\mathrm{NID}_{\mathrm{AF}-1}\right)$ that interacts with AF-1 of AR. GRIP1 enhances the activity of the tamoxifen-liganded ER by enhancing the activity of AF-1 but not by enhancing the activity of AF-2 (30). GRIP1 action requires each of the three AF-1 subregions (boxes 1, 2 and 3) and, especially, sequences within box 1 (30).

After p160 coactivators have bound to the DNAbound NR, they activate transcription machinery through two C-terminal activation domains (AD1 and AD2). AD1 interacts with $\mathrm{CBP} / \mathrm{p} 300$ (23, 32, 33). $\mathrm{CBP} / \mathrm{p} 300$ as well as $\mathrm{p} 160$ coactivators interact also with p/CAF (p300 and CBP-associated factor) (12, 34, 35). This complex containing p160 coactivator, CBP/ p300, and p/CAF activates transcription through its 
histone acetyltransferase activity $(12,35-38)$, and also by interacting with the basal transcription machinery $(11,39)$. AD2 interacts with coactivator-associated arginine methyltransferase 1 , which has been shown to methylate histone $\mathrm{H} 3$ in vitro, suggesting its ability to modify chromatin (40).

Glucocorticoids are used extensively in the treatment of skin diseases. Radoja et al. (41) have found that GRIP1 and SRC-1 are not involved in the GR complex that suppresses keratin genes, probably because they cannot function with monomers of GR or because there might be other, epidermis-specific coregulators rather than general ones. Carapeti et al. (42) have found a fusion between MOZ and TIF2 genes, which was specifically amplified from the acute myeloid leukemia (AML-M5) patient's bone marrow RNA, but not from bone marrow extracted from normal individuals. They have also partially characterized MOZ-TIF2 fusion in a further patient with AML and an inv(8)(p11q13) demonstrating rearrangements within both the MOZ and TIF2 genes and indicating the existence of breakpoint cluster regions within them (43). Ghadessy et al. (44) have screened the AR gene of 173 infertile men with the phenotype of severe oligospermia and three of them had a single M886V transition, which reduced TIF 2 coactivation function by approximately $40 \%$ in an AR-driven reporter system and in the mammalian twohybrid system. These examples indicate the importance and necessity of coactivators for normal cell functions.

TIF2 expression has been detected with Northern blotting in human pancreas, skeletal muscle, liver, lung, placenta, brain and heart and at a much lower level in kidney (7). Using the GRIP1 insert as a probe, Northern blot analyses identified RNA species of $\sim 9 \mathrm{~kb}$ and $7 \mathrm{~kb}$ in mouse 12- to 17-day-old embryos and in adult mouse brain, heart, lung, muscle, skin and spleen (8). GRIP1 RNA was also expressed in mouse liver, kidney and testis (9). Although these results suggest wide expression, they do not reveal the expression patterns within different organs, cell types or subcellular compartments. Thus, the aim of this study was to raise and characterize two novel polyclonal antibodies against GRIP1 (and TIF2) and to study GRIP1 expression in female and male murine tissues by immunohistochemistry and to find out the subcellular localization of endogenous GRIP1. We have also compared the expression of GRIP1 with PR expression (our previous results in Uotinen et al. (45)).

\section{Materials and methods}

\section{Production of GRIP1 antipeptide antibody}

New Zealand White rabbits were injected s.c. with $100 \mu \mathrm{g}$ synthetic peptide conjugated to thyroglobulin to produce antibodies against GRIP1/TIF2. One synthetic peptide $(\alpha 123)$ corresponds to the peptide sequence 34-47 (NH-Thr-Glu-Lys-Arg-Asn-Arg-GluGln-Glu-Asn-Lys-Tyr-Ile-Glu) and the other $(\alpha 124)$ to the residues 468-481 (NH-Asn-Ser-Pro-Ser-Gln-SerSer-Pro-Gly-Met-Asn-Pro-Gly-Gln) of GRIP1/TIF2. Corresponding sequences of GRIP1 and human TIF2 are identical. The first injection contained Freund's complete adjuvant and after 1 month the subsequent two antigen injections in incomplete adjuvant were repeated once a month. The serum was precipitated with $40 \%$ ammonium sulfate, and the resulting IgG fractions were termed $\alpha 123$ and $\alpha 124$ respectively. Peptide specificity and titer of the antisera were tested on microtiter plates (Nunc-Immuno Plate, MaxiSorp) coated with ovalbumin-conjugated peptide antigen.

\section{Animals}

Nine-week-old female NMRI mice $(n=12)$ were ovariectomized under anesthesia (fentanyl $0.0315 \mathrm{mg}$ and fluanisone $1 \mathrm{mg}$ (Hypnorm; Janssen-Cilag Ltd) and midazolam $0.1 \mathrm{mg}$ (Dormicum; Roche) injected s.c. in a ratio of $1: 1)$. After operation mice were injected s.c. with $9 \mu \mathrm{g}$ analgesic buprenorphine (Temgesic; Reckitt \& Colman). One week later six mice were treated daily with 17ß-estradiol-valerate (Sigma Chemical Co.) (10 $\mu \mathrm{g} / 100 \mathrm{~g}$ body weight) in sesame oil (H Lamotte, Germany) i.m. for 5 days. The other group of six mice received no treatment. The animals were killed by cervical dislocation at the age of 11 weeks, i.e. $24 \mathrm{~h}$ after the last injection, and tissue samples were taken immediately.

\section{Transfection of COS cells}

COS cells (African green monkey kidney cells) were transfected with TIF2 cDNA using electroporation as described previously (46). COS cells were grown in DMEM/F12 supplemented with $10 \%$ fetal bovine serum and plated at 50-60\% confluence in Petri dishes after transfection. TIF2 cDNA, subcloned into the eukaryotic expression vector pSG5 (47), was transiently transfected into the cells by the electroporation technique (InVitrogen, optimized electroporation protocol for COS cells, Electroporator II manual, Version A). The efficiency of the transfection was monitored by cotransfecting an internal control recombinant pCH110 (Pharmacia, Uppsala, Sweden) expressing $\beta$-galactosidase.

\section{Immunocytochemistry}

Transfected cells were transferred to glass coverslips and left to grow for $24 \mathrm{~h}$. Cells were fixed in $4 \%$ paraformaldehyde for $15 \mathrm{~min}$, washed in PBS (consisting of $0.9 \% \mathrm{NaCl}$ in $0.1 \mathrm{M}$ phosphate buffer) for $10 \mathrm{~min}$, incubated in $0.5 \%$ Triton-X 100 in PBS for $40 \mathrm{~min}$ at room temperature (RT, $18-22{ }^{\circ} \mathrm{C}$ ) and washed in PBS for $10 \mathrm{~min}$. They were then incubated 

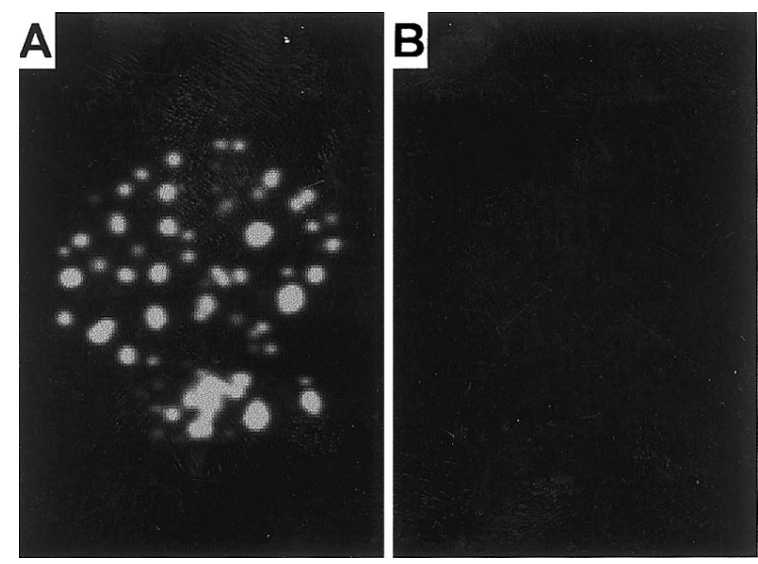

Figure 1 (A) COS cells transfected with GRIP1 cDNA show a distinct, clearly nuclear staining pattern when immunostained with $\alpha 123$. (B) Staining was not seen in COS cells transfected with pSG5 only.

in $10 \%$ normal horse serum in PBS for 30 min and after removal of the excess serum the primary antibodies were added and sections were incubated overnight at $4{ }^{\circ} \mathrm{C}$. Antibodies $\alpha 123$ and $\alpha 124$ were used at a final concentration of $2 \mu \mathrm{g} / \mathrm{ml}$ in $1 \%$ normal horse serum in PBS. Cells were washed in PBS for $10 \mathrm{~min}$ and incubated for $30 \mathrm{~min}$ at $37^{\circ} \mathrm{C}$ with fluorescein-anti-rabbit (Boehringer-Mannheim $\mathrm{GmbH}$, Mannheim, Germany) diluted 1:300 in PBS. Cells were then washed in PBS for $10 \mathrm{~min}$ and embedded in PBS:glycerol (3:1) containing $0.1 \%$ p-phenylenediamine $(48,49)$.

\section{Cytosol preparation and immunoblotting}

Cytosol preparation and immunoblotting were performed as described previously (50). Cells were harvested and collected into Eppendorf tubes $48 \mathrm{~h}$ after transfection, and lysed with $150 \mu \mathrm{l}$ cell lysis buffer $(20 \mathrm{mM}$ Hepes, pH 8.0, $20 \mathrm{mM} \mathrm{NaCl}, 0.5 \%$ Nodinet P-40, protease inhibitors (Complete Mini; Boehringer-Mannheim) and $1 \mathrm{mM}$ dithiothreitol). This was followed by $5 \mathrm{~min}$ incubation on ice and 1 min centrifugation at $16170 \boldsymbol{g}$, and the cytosolic fraction obtained was used in presaturation experiments. Total protein concentrations of the cytosol samples were determined using the Bradford method. Cytosol samples were mixed with 1 vol of $2 \times$ SDSsample buffer and boiled for $5 \mathrm{~min}$. Equal amounts of protein $(40 \mu \mathrm{g} / \mathrm{lane})$ were resolved in $6.5 \%$ polyacrylamide slab gels containing $0.1 \%$ SDS and transferred to nitrocellulose membrane using electrophoretic transfer (Mini Trans-blot; BioRad, Richmond, CA, USA). The membranes were presaturated with 5\% skimmed milk powder in TBS-Tween $(50 \mathrm{mM}$ Tris, $0.9 \%$ $\mathrm{NaCl}, \mathrm{pH} 8.0,0.05 \%$ Tween) and incubated with the primary antibody $\alpha 123$ or $\alpha 124(5.0 \mu \mathrm{g} / \mathrm{ml})$ in TBS-Tween containing 1\% skimmed milk powder at $4{ }^{\circ} \mathrm{C}$ overnight. After washing with TBS-Tween the membranes were incubated with peroxidase-conjugated goat anti-rabbit antibody (Cappel, West Chester, PA, USA) diluted 1:40 000 in TBS-Tween with $1 \%$ skimmed milk powder. The peroxidase was visualized using the enhanced chemiluminescence method following the manufacturer's instructions (ECL; Amersham International, Bucks, UK) with exposure times ranging from 1 to $20 \mathrm{~min}$.

\section{Immunohistochemistry}

Tissue samples were fixed in Baker's fixative $(4 \%$ paraformaldehyde, $\left.1 \% \mathrm{CaCl}_{2}, \mathrm{pH} 6.7\right)$ for $2 \mathrm{~h}$ at $4{ }^{\circ} \mathrm{C}$, dehydrated and embedded in paraffin. Sections $(5 \mu \mathrm{m})$ were cut, deparaffinized and rehydrated in graded ethanol. Thereafter the slices were incubated in citrate buffer ( $\mathrm{pH} 6.0)$ in a microwave oven $(1000 \mathrm{~W}$ power, rotating platform) for two 5 min periods. Incubation in

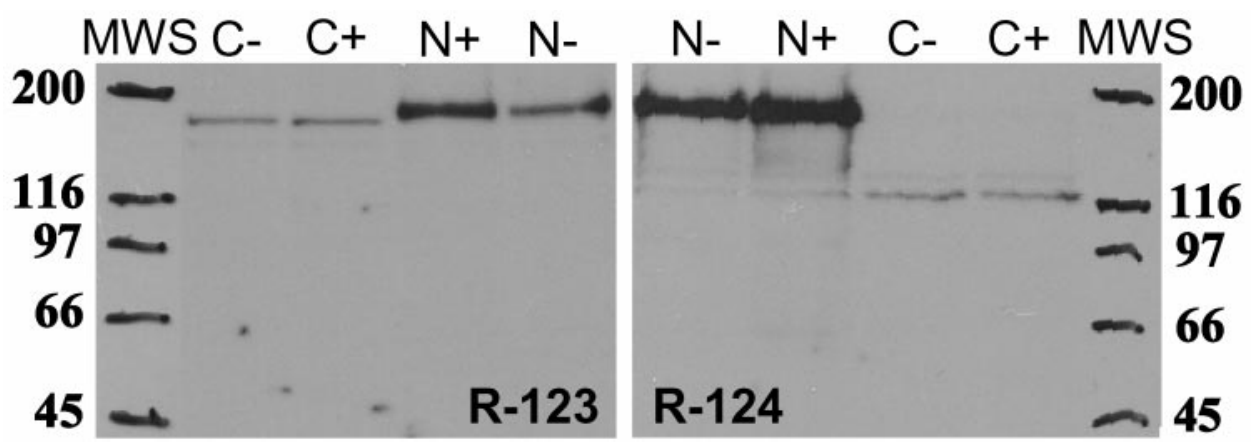

Figure 2 Cytoplasmic ('C') and nuclear fractions ('N') of COS cells either transfected with GRIP1 cDNA (+) or pSG5 only (-) immunoblotted with $\alpha 123$ and $\alpha 124$. A clear band was seen in the nuclear fraction of COS cells with both antibodies (bands $N-$ ), and transfection slightly but clearly increased the intensity of the staining (bands $\mathrm{N}+$ ). A band with lower intensity was also seen in the cytoplasmic fraction immunostained with $\alpha 123$ only, but transfection had no significant effect on the staining intensity. MWS = high range molecular weight standard. 

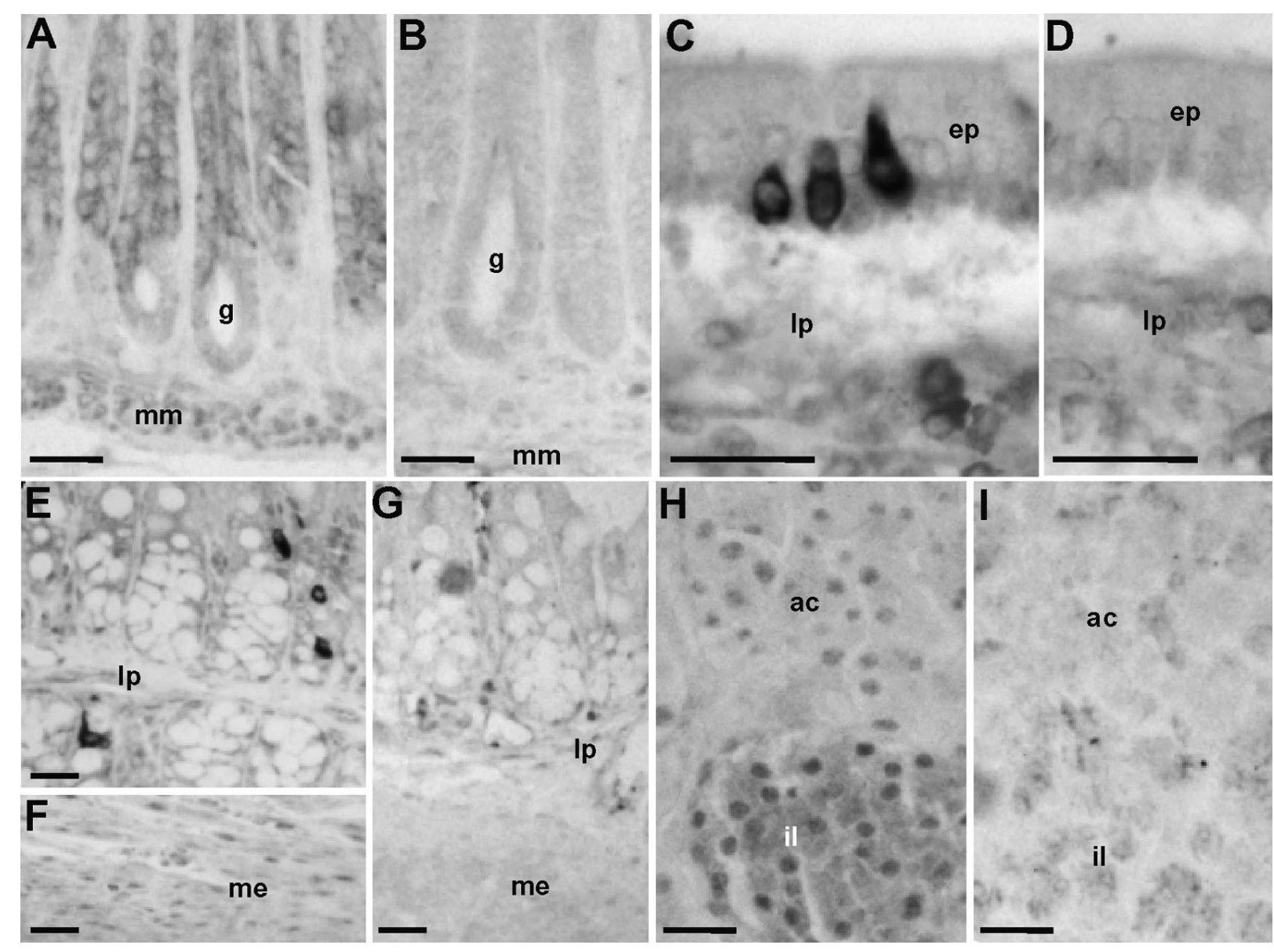

Figure 3 GRIP1 expression in some gastrointestinal organs of non-treated (A-D) and estrogen-treated (E-I) mice, immunostained with antibodies $\alpha 123(A-D)$ and $\alpha 124(E-I)$. In some epithelial cells of the stomach, cytoplasmic staining can be seen as well as nuclear staining in the smooth muscle cells of muscularis mucosae (A). Presaturation abolished the staining (B). Strong cytoplasmic staining is present in some epithelial cells of the duodenum (C), which is also abolished by presaturation (D). In the large intestine nuclear staining is evident in the muscular layer and lamina propria (E), and it is abolished by presaturation (F). Islets of Langerhans as well as some acinar cells of the pancreas have positive nuclear staining $(\mathrm{H})$, and pancreas stained with pre-immune serum is devoid of staining $(\mathrm{I})$. $\mathrm{g}$, gland; $\mathrm{mm}$, muscularis mucosae; ep, epithelium; Ip, lamina propria; me, muscularis externa; ac, acinar cells; il, islets of Langerhans. Bars represent $20 \mu \mathrm{m}$.

methanol containing $0.5 \%$ of $30 \% \mathrm{H}_{2} \mathrm{O}_{2}$ at RT blocked endogenous peroxidase activity of the tissues. The sections were then incubated with 10\% normal horse serum in PBS for $30 \mathrm{~min}$ at RT to reduce non-specific binding followed by incubation with the primary antibody ( $\alpha 123$ and $\alpha 124$, concentration $5 \mu \mathrm{g} / \mathrm{ml}$ ) in PBS containing 1\% normal horse serum overnight at $4{ }^{\circ} \mathrm{C}$. This was followed by incubation with the biotinylated goat anti-rabbit IgG (Vector) and avidinbiotin-peroxidase complex (Vector) for $30 \mathrm{~min}$ each. Peroxidase activity was visualized by diaminobenzidine $(\mathrm{DAB})$ as a substrate in the presence of $0.02 \% \mathrm{H}_{2} \mathrm{O}_{2}$ in $0.5 \mathrm{M}$ Tris, $\mathrm{pH}$ 7.6. Sections were dehydrated and mounted in Entellan (Merck KgaA, Darmstadt, Germany). An immunohistochemistry kit (Zymed) was used in some stainings, performed otherwise similarly, but the blocking solution, secondary antibody and avidin-biotin-peroxidase as well as DAB were provided in the kit.

To verify the specificity of immunostaining, primary antibody was either substituted with 1\% normal horse serum, PBS or pre-immune IgG (a negative control), or presaturated with an excess of the corresponding peptide conjugated to the ovalbumin (concentration $6 \mu \mathrm{g} / \mathrm{ml})$ for $4 \mathrm{~h}$ at $4{ }^{\circ} \mathrm{C}$.

\section{Results}

\section{Characterization of the antibodies}

When COS cells transiently transfected with GRIP1 were immunostained with antibodies $\alpha 123$ and $\alpha 124$, a distinct, clearly nuclear staining with dotted pattern 
was seen (Fig. 1A), while cells transfected with pSG5 only did not show any staining (Fig. 1B).

\section{Western blotting}

When cytosolic and nuclear fraction of COS cells were immunoblotted with the antibodies $\alpha 123$ and $\alpha 124$, a band with an approximate size of $160 \mathrm{kDa}$ was seen in both nuclear fractions (Fig. 2, lanes $\mathrm{N}-$ ). Transfection with GRIP1 cDNA clearly increased the intensity of both bands (Fig. 2, lanes N+). A band with lower intensity was seen in the cytoplasmic fraction of COS cells immunostained with $\alpha 123$ only (Fig. 2, lane $\mathrm{C}-$ ), and transfection had no significant effect on the staining intensity (Fig. 2, lane $\mathrm{C}+$ ).

\section{Immunohistochemistry}

Both antibodies gave similar staining pattern in the immunohistochemical staining of paraffin-embedded tissues, although staining with the antibody $\alpha 124$ resulted in stronger staining intensity than with $\alpha 123$ in exocrine epithelial cells of the pancreas and in the nuclei of blood vessels and tubular and glomerular epithelial cells of kidney. Female mice were ovariectomized and divided into two groups, one that received estradiol-valerate and the other that received no hormone treatment. According to our results, there were no differences in GRIP1 expression between these two groups. The specificity of the staining in each tissue was controlled by replacing the antibody with normal horse serum, PBS, or pre-immune IgG, none of which produced visible GRIP1 staining. Presaturation of the antibodies with corresponding peptide either abolished or clearly reduced the intensity of the staining, although staining was not reduced by presaturation in a few tissues, suggesting non-specific staining. The immunostaining was mostly seen in the nuclei, but cytoplasmic GRIP1 expression was seen in some cells as well. Both antibodies recognize mouse GRIP1 as well as human TIF2 (not shown).

\section{GRIP1 expression in gastrointestinal organs}

A weak GRIP1-positive staining was seen in the lamina propria and muscular layer of esophagus, and also basal parts of the epithelium had positive staining (not shown). Some of the epithelial cells had cytoplasmic staining in the stomach, while a nuclear staining was seen in the smooth muscle cells (Fig. 3A). In the small intestine some scattered epithelial cells had strong cytoplasmic staining with both antibodies (Fig. 3C). Also the external muscular layer of small intestine had clearly positive staining while lamina propria, muscularis mucosae and submucosa had very weak positive

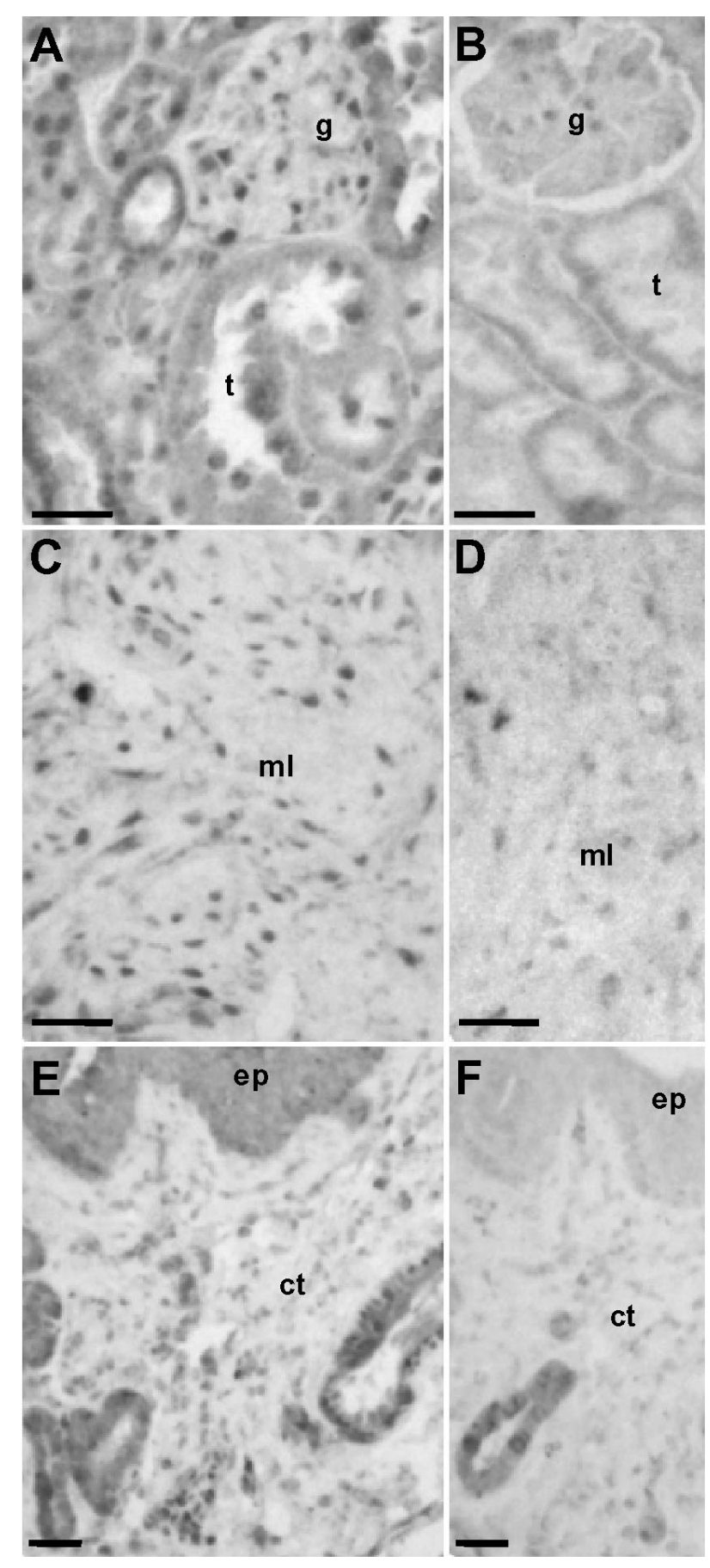

Figure 4 Urinary organs of non-treated $(A, B)$ and estrogen-treated $(C, D)$ female and male (E, F) mice stained with $\alpha 123(E, F)$ and $\alpha 124$ (A-D). There was a positive staining in the tubules and glomeruli of the kidney (A) and the staining was markedly reduced with presaturation (B). Detrusor muscle of the urinary bladder had strong staining (C), which was abolished by presaturation (D). Urethral connective tissue had positive nuclear staining $(E)$, and presaturation reduced it (F). t, tubule; g, glomerulus; ep, epithelium; $\mathrm{ct}$, connective tissue; ml, muscular layer. Bars represent $20 \mu \mathrm{m}$. 


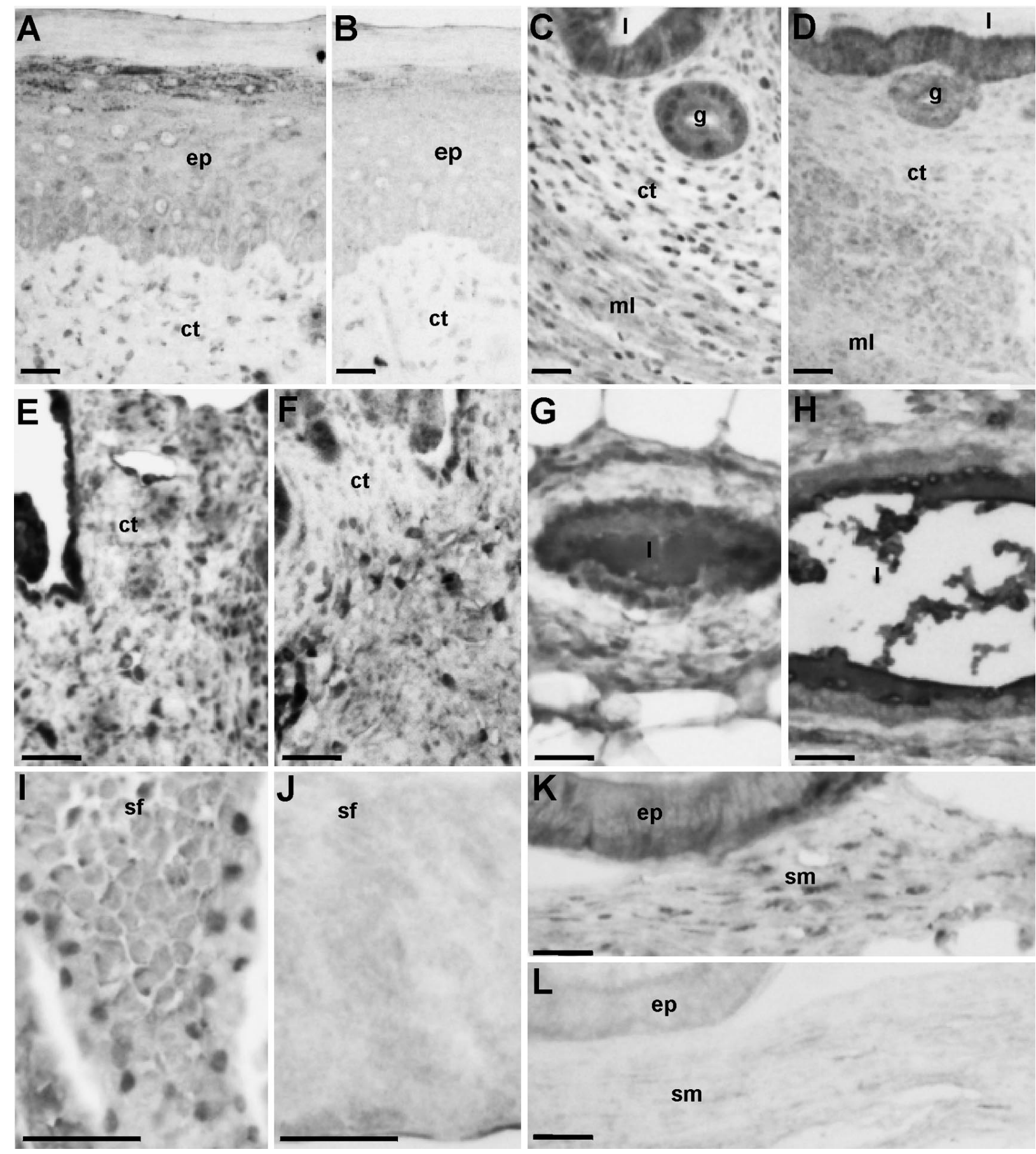

Figure 5 Genital organs of estrogen-treated $(A-D)$, non-ovariectomized $(E-H)$ and male $(I-L)$ mice stained with $\alpha 124(A-L)$. Connective tissue in the vagina was GRIP1-positive (A). Stromal and smooth muscle cells of uterus had positive staining and staining was also seen in the glandular epithelium while the luminal epithelium had a very weak staining (C). Connective tissue of the mesovarium had nuclear staining (E). In the ducts of mammary gland both basal epithelial cells and loose connective tissue cells surrounding the ducts were GRIP1-positive (G). Nuclear staining was seen in the basal parts of the seminiferous tubules (I). Ductus epididymis had nuclear staining in the surrounding smooth muscle cells $(\mathrm{L})$. Staining was clearly reduced by the presaturation $(B, D, F$, $\mathrm{H}$, J and L). Ep, epithelium; Ct, connective tissue; Ml, muscular layer; G, gland; L, lumen; SF, seminiferous tubule. Bars represent $20 \mu \mathrm{m}$. 
staining (not shown). Epithelial cells and external smooth muscle cells of cecum had mainly cytoplasmic staining (not shown). In the large intestine, similar scattered strong cytoplasmic staining was seen in the epithelium (not shown), and a clear nuclear staining was seen in the lamina propria and muscularis externa (Fig. 3E and F).

Ductal and acinar cells of the submandibular gland had positive nuclear staining (not shown). Parenchyme of the liver was devoid of immmunostaining, but hepatic ducts had nuclear staining in surrounding connective tissue and cytoplasmic staining in the epithelium (not shown), and also hepatic arteries were GRIP1-positive (not shown). In the pancreas a strong staining was seen in the islets of Langerhans (Fig. $3 \mathrm{H}$ ) with both antibodies, but exocrine epithelium was only weakly stained with antibody $\alpha 124$. Also blood vessels in the pancreas had positive staining (not shown), but pancreatic ducts were very weakly stained. Presaturation of the antibodies abolished or clearly reduced the staining in stomach (Fig. 3B), small intestine (Fig. 3D) and large intestine (Fig. 3G). Preimmune IgG produced no staining in the pancreas (Fig. 3I).

\section{GRIP1 expression in urogenital organs}

In the kidney, stained with the antibody $\alpha 124$, a nuclear staining could be seen in the tubular epithelium and in the glomerulus (Fig. 4A) as well as in blood vessels (not shown), but GRIP1 expression was not seen when stained with $\alpha 123$. Connective tissue cells in the capsule surrounding the kidney were GRIP1-positive with both antibodies (not shown). Ureter had a weak nuclear staining in the submucosa and muscular layer while epithelium had no staining (not shown). Urinary bladder had GRIP1 expression in the connective tissue underlying the epithelium (not shown) as well as in the muscular layer (Fig. 4C). Also some blood vessels and connective tissue surrounding the urinary bladder were GRIP1-positive (not shown). Urethra had nuclear staining in the epithelial cells as well as scattered nuclear staining in the mucosal connective tissue and muscular layer (Fig. 4E). Presaturation abolished the staining in the kidney (Fig. 4B), urinary bladder (Fig. 4D) and urethra (Fig. 4F).

Connective tissue in the vagina appeared to be GRIP1-positive while epithelium was devoid of specific staining (Fig. 5A). A clear nuclear staining was seen in the stromal and smooth muscle cells of the uterus as well as in the glandular epithelium, while luminal epithelium had only weak staining (Fig. 5C). Also some blood vessels and surrounding connective tissue were GRIP1-positive (not shown). Germinal and follicular epithelium of the ovary had non-specific cytoplasmic staining (not shown), and connective tissue in the cortex and medulla was negative. Connective tissue of mesovarium had clear nuclear staining (Fig. 5E). In the
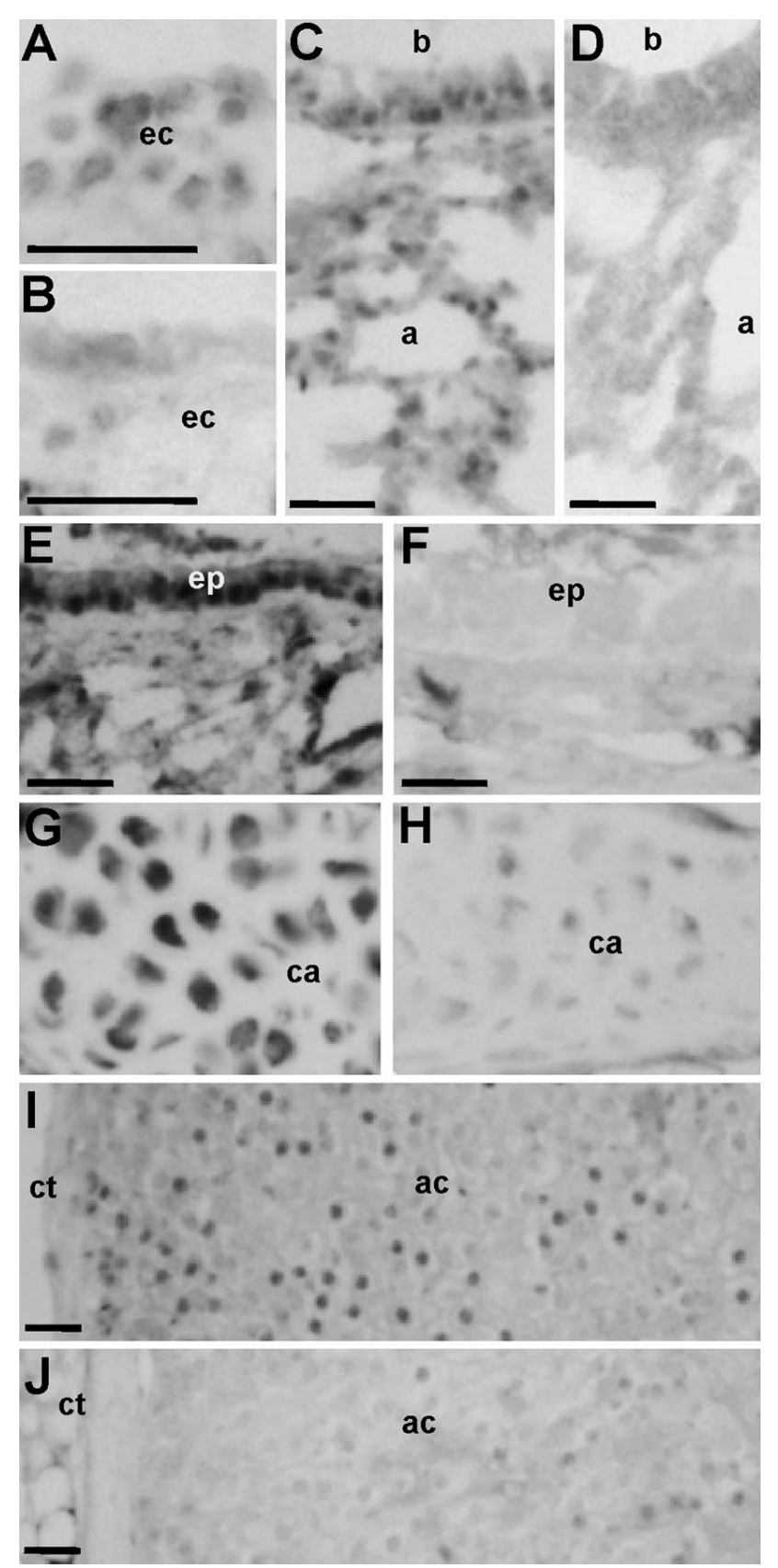

Figure 6 Organs of estrogen-treated mice stained with $\alpha 124$. In the heart, immunostaining was seen in endocardium (A). There was a positive staining in the bronchioles and alveoli of the lungs (C), which was not present when stained with preimmune serum (D). Nuclear staining was observed in the epithelium and cartilage of the trachea $(E, G)$. Adrenal cortex is GRIP1-positive (I). Presaturation clearly reduced the staining in heart $(B)$, trachea $(F, H)$ and adrenal cortex $(J)$. ec, endocardium; a, alveoli; b, bronchiole; ep, epithelium; ca, cartilage; ct, connective tissue; ac, adrenal cortex. Bars represents $20 \mu \mathrm{m}$. 
mammary gland, basal epithelial cells of the ducts as well as surrounding loose connective tissue cells had positive nuclear staining (Fig. 5G). Also adipocytes had nuclear staining (not shown).

In the seminiferous tubules of testis a nuclear staining was seen in the spermatogonia (Fig. 5I) and Sertoli cells (not shown). No specific staining was seen in the tunica albuginea (not shown). In the ductus epididymis a nuclear staining was seen in the smooth muscle cells (Fig. 5K), while ductuli efferentes were negative. Capsule was negative (not shown). A clear nuclear staining was seen in the fibroelastic capsule and fibromuscular stroma of prostate, and cytoplasmic staining was seen in the epithelium of the tubuloalveolar glands (not shown). Staining was clearly reduced in the presaturation controls of vagina (Fig. 5B), uterus (Fig. 5D), ovary (Fig. 5F), mammary gland (Fig. 5H), testis (Fig. 5J) and epididymis (Fig. 5L).

\section{GRIP1 expression in cardiovascular organs and respiratory tract}

Nuclear staining was seen in the endocardium (Fig. 6A) and myocardium (not shown) of the heart when stained with both antibodies. Presaturation of the antibody $\alpha 124$ clearly reduced the staining (Fig. 6B), but presaturation of the antibody $\alpha 123$ had no effect on the staining intensity. Positive staining, which was absent in the control staining, was also seen in some arteries and veins of the heart as well as in the pericardium (not shown). Many blood vessels in different organs as well as in the connective tissue surrounding many organs had positive staining in the tunica media and in the endothelium.

Epithelial cells of the alveoli and bronchioles were clearly positive, and there was also a weak scattered staining in the smooth muscle cells of the smaller airways (Fig. 6C). Blood vessels in the lungs were also GRIP1-positive (not shown). In the trachea, GRIP1 expression was detected in the nuclei of epithelial, smooth muscle and connective tissue cells as well as in the cartilage (Fig. 6E and G). There was no GRIP1 expression in the lungs when stained with pre-immune IgG (Fig. 6D). Presaturation control of the trachea was devoid of immunostaining (Fig. 6F and $\mathrm{H}$ ).

\section{GRIP1 expression in immunological and endocrinological organs}

There were two kinds of a staining in the thymus; some cells had a clear cytoplasmic staining, which was unaffected by the presaturation, while other cells had a very weak nuclear staining, which was abolished by the presaturation (not shown). Similar staining was also seen in the spleen; some cells had cytoplasmic staining, which was also present in control sections, and some cells had a nuclear staining which was not present in controls (not shown). Adrenal cortex had positive staining (Fig. 6I) and presaturation clearly reduced the staining (Fig. 6J). Adrenal capsule and medulla were devoid of staining (not shown). Thyroid gland cells did not show any specific staining (not shown). Striated muscle cells were GRIP1-negative in our study (not shown).

\section{Discussion}

When COS cells transiently transfected with GRIP1 were immunostained with antibodies $\alpha 123$ and $\alpha 124$, a clearly nuclear but special staining pattern was seen (Fig. 1). A similar staining pattern has also been described in a study by Voegel et al. (7); transiently overexpressed full-length human TIF2 protein was nuclear, mainly localized in discrete bodies resembling nuclear bodies. When we studied endogenous murine GRIP1 expression, mainly nuclear, but also cytoplasmic staining pattern was seen, suggesting that the fulllength GRIP1 might not be solely nuclear. This raises the question of how the subcellular localization of cofactors is regulated. Most nuclear proteins shuttle between cytoplasm and nucleus - some of them in a regulated manner - and the subcellular location thus affects or determines the function of these proteins (51, 52). Although the N-terminal charged cluster in the TIF2 coding sequence harbors putative bipartite nuclear localization signals (7), the mechanism by which GRIP1 is transported into the nucleus is not yet known.

Northern blot analyses have identified RNA species of $\sim 9 \mathrm{~kb}$ and $7 \mathrm{~kb}$ in mouse 12- to 17-day-old embryos and in adult mouse brain, heart, lung, muscle, skin and spleen (8). GRIP1 RNA was also expressed in mouse liver, kidney and testis (9). Expression of TIF2 transcript was found in several human tissues including pancreas, skeletal muscle, liver, lung, placenta, brain and heart, and at a much lower level in kidney (7), suggesting wide expression. However, our immunohistochemical results show that GRIP1 expression varies markedly between different organs and cell types. In gastrointestinal organs, GRIP1 expression was mainly seen in epithelial and smooth muscle cells, but in urinary tract organs mainly in stromal and smooth muscle cells. GRIP1 expression in genital area was mainly seen in epithelial and stromal cells. The islets of Langerhans in the pancreas were strongly stained, but pancreatic ducts and exocrine epithelial cells were only weakly stained. Liver parenchymal cells were clearly negative and positive cells were found in some hepatic arteries and connective tissue cells surrounding hepatic ducts, and, in addition to thyroid gland, there was no GRIP1 expression in skeletal muscle cells - the only discrepancy between our results and those of Voegel et al. (7) and Hong et al. (9). However, Chen et al. (53) have shown recently that GRIP1 mRNA was constitutively expressed in 
proliferating myoblasts and that the levels of GRIP1 protein increase during myogenesis. They conclude that GRIP1 is required for the formation of post-mitotic cells that express myofibrillar proteins and is thus involved in the regulation of myogenic differentiation.

Human TIF2 was originally found as a protein which interacts with nuclear receptors in an agonistdependent manner and it is a mediator for the liganddependent activation function AF-2 of NRs (7). Hong et al. (9) have showed that full-length GRIP1 interacts with the hormone-binding domain of PR, a steroid receptor which is a member of the nuclear receptor superfamily. We have previously studied the expression of PR in female murine organs (45), and when we compared the expression of PR and GRIP1 our data indicated that most PR-expressing cells also express GRIP1. However, although stromal and epithelial cells of vagina and epithelial cells of uterus expressed PR only after estrogen treatment, GRIP1 expression was not seen in the epithelial cells of vagina, and clearly weaker staining was seen in the glandular epithelial cells of the uterus. Stromal cells of vagina and uterus in turn clearly expressed GRIP1. Tissue recombination experiments using tissues from ER- and PR-null mice have shown that regulation of gene expression and cell proliferation in the uterine epithelium is largely regulated by steroid receptors in the stromal cells whereas the receptor expression in the epithelium seems to be largely dispensable (54-56). It is thus interesting to speculate that the low expression level of GRIP1 in the epithelium might contribute to this relative steroid insensitivity of the uterine and vaginal epithelium.

\section{Acknowledgements}

R P and N S contributed equally to this work. We want to thank Dr H Gronemeyer and his collaborators in the Institut de Génétique et de Biologie Moléculaire et Cellulaire for providing the human TIF2 cDNA.

\section{References}

1 Evans RM. The steroid and thyroid hormone receptor superfamily. Science $1988 \mathbf{2 4 0} 889-895$.

2 Durand B, Saunders M, Gaudon C, Roy B, Losson R \& Chambon P. Activation function 2 (AF-2) of retinoic acid receptor and 9-cis retinoic acid receptor: presence of a conserved autonomous constitutive activating domain and influence of the nature of the response element on AF-2 activity. EMBO Journal 199413 5370-5382.

3 Hollenberg SM \& Evans RM. Multiple and cooperative transactivation domains of the human glucocorticoid receptor. Cell 198855 899-906.

4 Kumar V, Green S, Stack G, Berry M, Jin JR \& Chambon P. Functional domains of the human estrogen receptor. Cell 1987 51 941-951.

5 Horwitz KB, Jackson TA, Bain DL, Richer JK, Takimoto GS \& Tung L. Nuclear receptor coactivators and corepressors. Molecular Endocrinology $1996 \mathbf{1 0} 1167-1177$.
6 Glass CK, Rose DW \& Rosenfeld MG. Nuclear receptor coactivators. Current Opinion in Cell Biology $19979222-232$.

7 Voegel JJ, Heine MJ, Zechel C, Chambon P \& Gronemeyer H. TIF2, a $160 \mathrm{kDa}$ transcriptional mediator for the ligand-dependent activation function AF-2 of nuclear receptors. EMBO Journal $1996153667-3675$.

8 Hong H, Kohli K, Trivedi A, Johnson DL \& Stallcup MR. GRIP1, a novel mouse protein that serves as a transcriptional coactivator in yeast for the hormone binding domains of steroid receptors. PNAS 199693 4948-4952.

9 Hong H, Kohli K, Garabedian MJ \& Stallcup MR. GRIP1, a transcriptional coactivator for the AF-2 transactivation domain of steroid, thyroid, retinoid, and vitamin D receptors. Molecular and Cellular Biology 199717 2735-2744.

10 Onate SA, Tsai SY, Tsai MJ \& O'Malley BW. Sequence and characterization of a coactivator for the steroid hormone receptor superfamily. Science 1995 270 1354-1357.

11 Takeshita A, Yen PM, Misiti S, Cardon GR, Liu Y \& Chin WW. Molecular cloning and properties of a full-length putative thyroid hormone receptor coactivator. Endocrinology 1996137 3594-3597.

12 Chen H, Lin RJ, Schiltz RL, Chakravarti D, Nash A, Nagy L et al. Nuclear receptor coactivator ACTR is a novel histone acetyltransferase and forms a multimeric activation complex with $\mathrm{P} / \mathrm{CAF}$ and $\mathrm{CBP} / \mathrm{p} 300$. Cell 199790 569-580.

13 Anzick SL, Kononen J, Walker RL, Azorsa DO, Tanner MM, Guan XY et al. AIB1, a steroid receptor coactivator amplified in breast and ovarian cancer. Science 1997 277 965-968.

14 Takeshita A, Cardona GR, Koibuchi N, Suen CS \& Chin WW. TRAM-1, a novel 160-kDa thyroid hormone receptor activator molecule, exhibits distinct properties from steroid receptor coactivator-1. Journal of Biological Chemistry $1997 \mathbf{2 7 2}$ 27629-27634.

$15 \mathrm{Li} \mathrm{H}$, Gomes PJ \& Chen JD. RAC3, a steroid/nuclear receptorassociated coactivator that is related to SRC-1 and TIF2. PNAS $1997948479-8484$.

16 Torchia J, Rose DW, Inostroza J, Kamei Y, Westin S, Glass CK et al. The transcriptional co-activator $\mathrm{p} / \mathrm{CIP}$ binds CBP and mediates nuclear-receptor function. Nature $1997 \quad \mathbf{3 8 7}$ 677-684 [see comments].

17 Treuter E, Johansson L, Thomsen JS, Warnmark A, Leers J, PeltoHuikko $\mathrm{M}$ et al. Competition between thyroid hormone receptorassociated protein (TRAP) 220 and transcriptional intermediary factor (TIF) 2 for binding to nuclear receptors. Implications for the recruitment of TRAP and p160 coactivator complexes. Journal of Biological Chemistry 1999274 6667-6677.

18 Atkins GB, Hu X, Guenther MG, Rachez C, Freedman LP \& Lazar MA. Coactivators for the orphan nuclear receptor RORalpha. Molecular Endocrinology 199913 1550-1557.

19 Hong H, Yang L \& Stallcup MR. Hormone-independent transcriptional activation and coactivator binding by novel orphan nuclear receptor ERR3. Journal of Biological Chemistry $199927422618-22626$.

20 Sladek FM, Ruse MD Jr, Nepomuceno L, Huang SM \& Stallcup MR. Modulation of transcriptional activation and coactivator interaction by a splicing variation in the $\mathrm{F}$ domain of nuclear receptor hepatocyte nuclear factor 4alpha1. Molecular and Cellular Biology $1999 \quad 19$ 6509-6522 [in process citation].

21 Yang C \& Chen S. Two organochlorine pesticides, toxaphene and chlordane, are antagonists for estrogen-related receptor alpha-1 orphan receptor. Cancer Research 199959 4519-4524.

22 Heery DM, Kalkhoven E, Hoare S \& Parker MG. A signature motif in transcriptional co-activators mediates binding to nuclear receptors. Nature $1997 \mathbf{3 8 7} 733-736$ [see comments].

23 Voegel JJ, Heine MJ, Tini M, Vivat V, Chambon P \& Gronemeyer H. The coactivator TIF2 contains three nuclear receptor-binding motifs and mediates transactivation through CBP bindingdependent and -independent pathways. EMBO Journal 199817 507-519. 
24 Schmidt S, Baniahmad A, Eggert M, Schneider S \& Renkawitz R. Multiple receptor interaction domains of GRIP1 function in synergy. Nucleic Acids Research 199826 1191-1197.

25 Leers J, Treuter E \& Gustafsson JA. Mechanistic principles in NR box-dependent interaction between nuclear hormone receptors and the coactivator TIF2. Molecular and Cellular Biology 199818 6001-6013.

26 Ding XF, Anderson CM, Ma H, Hong H, Uht RM, Kushner PJ et al. Nuclear receptor-binding sites of coactivators glucocorticoid receptor interacting protein 1 (GRIP1) and steroid receptor coactivator 1 (SRC-1): multiple motifs with different binding specificities. Molecular Endocrinology 199812 302-313.

27 Hong H, Darimont BD, Ma H, Yang L, Yamamoto KR \& Stallcup MR. An additional region of coactivator GRIP1 required for interaction with the hormone-binding domains of a subset of nuclear receptors. Journal of Biological Chemistry $1999 \mathbf{2 7 4}$ 3496-3502.

28 Feng W, Ribeiro RC, Wagner RL, Nguyen H, Apriletti JW, Fletterick RJ et al. Hormone-dependent coactivator binding to a hydrophobic cleft on nuclear receptors. Science $1998 \mathbf{2 8 0}$ 1747-1749.

29 Onate SA, Boonyaratanakornkit V, Spencer TE, Tsai SY, Tsai MJ, Edwards DP et al. The steroid receptor coactivator-1 contains multiple receptor interacting and activation domains that cooperatively enhance the activation function 1 (AF1) and AF2 domains of steroid receptors. Journal of Biological Chemistry 1998 273 12101-12108.

30 Webb P, Nguyen P, Shinsako J, Anderson C, Feng W, Nguyen MP et al. Estrogen receptor activation function 1 works by binding p160 coactivator proteins. Molecular Endocrinology 199812 $1605-1618$.

31 Ma H, Hong H, Huang SM, Irvine RA, Webb P, Kushner PJ et al. Multiple signal input and output domains of the 160-kilodalton nuclear receptor coactivator proteins. Molecular and Cellular Biology $1999196164-6173$.

32 Kamei Y, Xu L, Heinzel T, Torchia J, Kurokawa R, Gloss B et al. CBP integrator complex mediates transcriptional activation and AP-1 inhibition by nuclear receptors. Cell 199685 403-414.

33 Chakravarti D, LaMorte VJ, Nelson MC, Nakajima T, Schulman IG, Juguilon $\mathrm{H}$ et al. Role of CBP/P300 in nuclear receptor signalling. Nature $1996 \mathbf{3 8 3}$ 99-103 [see comments].

34 Korzus E, Torchia J, Rose DW, Xu L, Kurokawa R, McInerney EM et al. Transcription factor-specific requirements for coactivators and their acetyltransferase functions. Science $1998 \mathbf{2 7 9}$ 703-707.

35 Yang XJ, Ogryzko VV, Nishikawa J, Howard BH \& Nakatani Y. A p300/CBP-associated factor that competes with the adenoviral oncoprotein E1A. Nature 1996382 319-324.

36 Spencer TE, Jenster G, Burcin MM, Allis CD, Zhou J, Mizzen CA et al. Steroid receptor coactivator-1 is a histone acetyltransferase. Nature 1997389 194-198.

37 Ogryzko VV, Schiltz RL, Russanova V, Howard BH \& Nakatani Y. The transcriptional coactivators $\mathrm{p} 300$ and CBP are histone acetyltransferases. Cell 199687 953-959.

38 Bannister AJ \& Kouzarides T. The CBP co-activator is a histone acetyltransferase. Nature $1996 \mathbf{3 8 4} 641-643$.

39 Swope DL, Mueller CL \& Chrivia JC. CREB-binding protein activates transcription through multiple domains. Journal of Biological Chemistry $199627128138-28145$.

40 Chen D, Ma H, Hong H, Koh SS, Huang SM, Schurter BT et al. Regulation of transcription by a protein methyltransferase. Science $1999 \mathbf{2 8 4} 2174-2177$.
41 Radoja N, Komine M, Jho SH, Blumenberg M \& Tomic-Canic M. Novel mechanism of steroid action in skin through glucocorticoid receptor monomers. Molecular and Cellular Biology 200020 $4328-4339$.

42 Carapeti M, Aguiar RC, Goldman JM \& Cross NC. A novel fusion between MOZ and the nuclear receptor coactivator TIF2 in acute myeloid leukemia. Blood 199891 3127-3133.

43 Carapeti M, Aguiar RC, Watmore AE, Goldman JM \& Cross NC. Consistent fusion of MOZ and TIF2 in AML with inv(8)(p11q13). Cancer Genetics and Cytogenetics 1999113 70-72.

44 Ghadessy FJ, Lim J, Abdullah AA, Panet-Raymond V, Choo CK, Lumbroso $\mathrm{R}$ et al. Oligospermic infertility associated with an androgen receptor mutation that disrupts interdomain and coactivator (TIF2) interactions. Journal of Clinical Investigation $19991031517-1525$.

45 Uotinen N, Puustinen R, Pasanen S, Manninen T, Kivineva M, Syvälä $\mathrm{H}$ et al. Distribution of progesterone receptor in female mouse tissues. General and Comparative Endocrinology 1999115 429-441.

46 Neumann E, Schaefer-Ridder M, Wang Y \& Hofschneider PH. Gene transfer into mouse lyoma cells by electroporation in high electric fields. EMBO Journal 19821 841-844.

47 Green S, Issemann I \& Sheer E. A versatile in vivo and in vitro eukaryotic expression vector for protein engineering. Nucleic Acids Research 198816369.

48 Johnson DG \& de C Nouguerira Araugo GM. A simple method of reducing the fading of immunofluorescence during microscopy. Journal of Immunological Methods 198143 349-350.

49 Platt JL \& Michael AF. Retardation of fading and enhancement of intensity of immunofluorescence by $p$-phenylenediamine. Journal of Histochemistry and Cytochemistry 198331 840-842.

50 Pasanen S, Ylikomi T, Syvälä H \& Tuohimaa P. Distribution of progesterone receptor in chicken: novel target organs for progesterone and estrogen action. Molecular and Cellular Endocrinology 1997135 79-91.

51 Nigg EA. Nucleocytoplasmic transport: signals, mechanisms and regulation. Nature 1997386 779-787.

52 Weis K. Importins and exportins: how to get in and out of the nucleus. Trends in Biochemical Sciences 199823 185-189 [published erratum appears in Trends in Biochemical Sciences $199823235]$.

53 Chen SL, Dowhan DH, Hosking BM \& Muscat GE. The steroid receptor coactivator, GRIP-1, is necessary for MEF-2C-dependent gene expression and skeletal muscle differentiation. Genes and Development 200014 1209-1228.

54 Brisken C, Park S, Vass T, Lydon JP, O'Malley BW \& Weinberg RA. A paracrine role for the epithelial progesterone receptor in mammary gland development. PNAS 199895 $5076-5081$.

55 Cooke PS, Buchanan DL, Young P, Setiawan T, Brody J, Korach KS et al. Stromal estrogen receptors mediate mitogenic effects of estradiol on uterine epithelium. PNAS 199794 6535-6540.

56 Kurita T, Lee KJ, Cooke PS, Lydon JP \& Cunha GR. Paracrine regulation of epithelial progesterone receptor and lactoferrin by progesterone in the mouse uterus. Biology of Reproduction 2000 $62831-838$

Received 19 December 2000

Accepted 9 May 2001 